\title{
Cell based therapy aides in infection and inflammation resolution in the murine model of cystic fibrosis lung disease
}

\author{
Tracey L. Bonfield ${ }^{1,2^{*}}$, Donald Lennon ${ }^{3}$, Santosh K. Ghosh ${ }^{4}$, Amy M. DiMarino $^{1,5}$, \\ Aaron Weinberg ${ }^{4}$, Arnold I. Caplan ${ }^{2,3}$ \\ ${ }^{1}$ Department of Pediatric Pulmonology, Case Western Reserve University, Cleveland, USA; \\ *Corresponding Author: Tracey.Bonfield@,case.edu \\ ${ }^{2}$ National Center for Regenerative Medicine, Case Western Reserve University, Cleveland, USA \\ ${ }^{3}$ Skeletal Research Center, Case Western Reserve University, Cleveland, USA \\ ${ }^{4}$ School of Dental Medicine, Case Western Reserve University, Cleveland, USA \\ ${ }^{5}$ Department of Pediatric Pulmonology, Rainbow Babies and Children's Hospital, Cleveland, USA
}

Received 17 January 2013; revised 25 February 2013; accepted 25 March 2013

Copyright (C) 2013 Tracey L. Bonfield et al. This is an open access article distributed under the Creative Commons Attribution License, which permits unrestricted use, distribution, and reproduction in any medium, provided the original work is properly cited.

\begin{abstract}
Cystic fibrosis (CF) is a genetically inherited disease which is characterized by excessive inflammation and inability to resolve infection with pathogens such as Pseudomonas aeruginosa. Treatment options have improved with correctors and potentiators, but a cure remains elusive. Human mesenchymal stem cells (hMSCs) have the potential to be both anti-inflammatory and anti-microbial, which makes them ideal candidates for exploration as an innovative new therapeutic for CF. Using a sublethal CF mouse model of chronic Pseudomonas aeruginosa infection, we show that hMSCs and wild type bone marrow derived macrophages (BMM) have the capacity to attenuate inflammation while at the same time improving the ability to resolve infection. Animals infected with bacteria and treated with hMSCs and BMM had less weight lost, decreased pro-inflammatory cytokines, decreased severity of gross lung pathology as well as clinical score. Importantly, even though the inflammation was decreased in vivo, both BMM and hMSC treatment resulted in significant decrease in lung bacterial load. The improvement in the CF model was consistent with hMSC induced anti-inflammatory and anti-microbial activity which may involve the cathelicidin LL-37. These studies suggest that both healthy MSCs and BMM may provide important new direction toward cell based therapies in CF.
\end{abstract}

Keywords: Inflammation; Mesenchymal Stem Cells; Antimicrobial Activity

\section{INTRODUCTION}

Cystic fibrosis is a genetically inherited disease which results in premature death and decreased quality of life [1]. The genetic anomaly is associated with defects in the expression of the gene which codes for the cystic fibrosis transmembrane regulator (CFTR). CFTR is a chloride channel which provides the efficient transfer of ions across epithelial cell membranes. Although many of the clinical complications from the lack of CFTR can be treated with pharmacologic and mechanical interventions, pulmonary complications continue to be a major source of morbidity and mortality [2]. Pharmacological interventions, gene therapy and antibiotics are the focus of clinical applications for CF therapeutics. The balance in CF pharmacologic therapy in lieu of a cure is the attenuation of the damaging inflammatory response while not increasing the susceptibility of CF patients to infection with pathogens such as Pseudomonas aeruginosa [3].

Human MSCs (hMSCs) are pleiotropic multipotent non-hematological progenitors that have the capacity to contribute to the attenuation of inflammation [4] while directly augmenting bactericidal killing [5]. These two properties of hMSCs along with their multi-potent nature and proposed "immune-privileged" properties make hMSCs an ideal candidate for therapeutic exploration in CF. hMSCs are capable of differentiating into a number of phenotypes, which include bone, cartilage, muscle, 
marrow, tendon/ligament, adipocytes and connective tissue [6]. hMSCs are well tolerated across species [6,7], minimizing the need for immunosuppression, which is appealing in $\mathrm{CF}$ due to the prevalence of co-existing chronic bacterial infection with pathogens such as Pseudomonas aeruginosa. It is important to note that in all of the clinical usages of human adult marrow-derived culture-expanded hMSCs, whether autologous or allogeneic hMSCs, no adverse events have been recorded [8]. Another important phenotype of hMSCs is their intrinsic capacity to secrete cytokines and growth factors at sites of tissue injury and inflammation suggesting that hMSCs may actively regulate the surrounding milieu in which they reside in vivo $[9,10]$. We have used mice which have been genetically modified so that they do not express functional Cftr. These animals when chronically infected with Pseudomonas aeruginosa demonstrate cachexia, pulmonary inflammation and inability to efficiently resolve infection. Our results suggest that hMSCs and BMM have the capacity to tone down pulmonary inflammation while at the same time aiding in infection resolution, potentially through enhancing BAL levels of the cathelicidin LL-37. The mechanisms of these effects involve both anti-inflammatory and anti-microbial soluble factors in the hMSC supernatants which might include LL-37. Further, our studies also suggest a potential benefit of using corrected BMM cells to aide in infection and inflammation resolution in CF. These studies implicate the significant potential of cell based therapy as an adjunct therapeutic in the treatment of cystic fibrosis lung infection and inflammation providing an exciting exploration of hMSCs and BMM for cell-based therapy in $\mathrm{CF}[11,12]$.

\section{METHODS}

\subsection{Mice}

All procedures involving mice were reviewed and approved by Case Western Reserve University, Institutional Animal Care and Use Committee. Case Western Reserve University Animal Assurance \#: A3145-01, with IACUC \# 2011-0145. All experiments used the congenic B6.129S6-Cftr ${ }^{\text {th2Uth }}(\mathrm{R} 117 \mathrm{H} / \mathrm{R} 117 \mathrm{H}$ mutation) and C57 BL/6 J controls (WT). Cftr ${ }^{\text {tm2Uth }}$ mice are a type IV Cftr mutant which predominantly affects the pulmonary response to infections. These animals were chosen to specifically investigate the potential proof of concept toward treating the pulmonary consequences of $\mathrm{CF}$ with cell based therapies. To study the therapeutic potential of hMSCs we used a sub-lethal model of airway infection and inflammation without the confounding contribution of gastrointestinal fragility. When chronically infected with Pseudomonas aeruginosa, the $\mathrm{Cftr}^{\text {tm2Uth }}$ mice demonstrated cachexia, weight loss and bronchoalveolar lavage (BAL) changes in cellular differential and cyto- kines without significant mortality. We have used 3 different groups of $C f t r^{t m 2 U t h}$ or controls mice for each of 3 different hMSC preparations. In each experiment, we utilized 5 - 8 mice. In a smaller set of studies $(n=2,5-7$ animals/group) we had the availability to explore the use of hMSCs in Cftr ${ }^{\text {tmlUth }}$ (DF508, B6.129S6-Cftr ${ }^{t m 1 K t h}$ ) mice at day 3. The $C f t r^{\text {tm } 1 K t h}$ mice (a type II mutation of $C f t r)$ have all of the manifestations of the CF knockout mouse with gastrointestinal blockage and hypersensitivity to bacterial infection. The groups included both $C f t r$ deficient and WT mice: infected without cell based therapy, infected with hMSCs or infected with WT BMM.

\subsection{Murine Model of CF Infection and Inflammation}

To generate a transient chronic infection, mice were infected with $5 \times 10^{5}$ colony-forming units (CFU) Pseudomonas aeruginosa, strain PA-M5715 (a mucoidal clinical isolate) embedded in agarose beads and suspended in $20 \mu \mathrm{L}$ of PBS $[13,14]$. All preparations of Pseudomonas aeruginosa impregnated beads were evaluated for relative colony forming units (CFUs) prior to inoculation into the mice. Cftr ${ }^{t m 2 U t h}, C f t r^{t m 1 K t h}$ and WT mice were anesthetized and then inoculated with bacteria into the trachea with a plastic catheter angled toward the right mainstream bronchus [13]. Brochoalveolar lavage (BAL) and whole lung homogenates were evaluated for CFUs at either day 3 or day 10 (post-hMSCs).

\subsection{Lung Inflammation}

Mice were injected with ketamine $(80 \mathrm{mg} / \mathrm{kg})$ and $\mathrm{xy}-$ lazine $(10 \mathrm{mg} / \mathrm{kg})$ as previously described [15]. The thoracic cavity was opened and the lungs exposed followed by insertion of a cannula through the trachea into the bronchi and infusion of $1 \times 1 \mathrm{ml}$ of warm PBS containing $0.2 \%$ lidocaine to do the BAL. The BAL fluid sample was recovered by aspirating the liquid with a syringe for total cell count and cellular differential. BAL fluid was aliquoted and analyzed for cytokines involved in CF pathophysiology by Luminex multi-analyte technology and LL-37 by a commercial kit (Hycult Biotech, Plymouth Meeting, PA. Cat \# HK321).

\subsection{Clinical and Lung Pathology Scores}

Mice were assessed daily for clinical score which was based upon coat quality, posture, ability to right themselves after being placed in lateral recumbence, ambulation and body weight (Table 1). At 3 days, 10 days, post-mortem or at sacrifice lungs were isolated and assessed for gross lung pathology in addition to quantitative bacteriology (Table 1). Both gross lung pathology and clinical scores were done by two different individuals who did not know the identity of the treatment groups. 
Table 1. Key to clinical and gross lung pathology scores.

\begin{tabular}{ccc}
\hline Score & Clinical Score Criteria & Gross Lung Pathology Criteria \\
\hline 0 & $\begin{array}{c}\text { healthy appearance, } \\
\text { normal activity } \\
\text { slightly scruffy or } \\
\text { scruffy appearance }\end{array}$ & within normal limits \\
1 & $\begin{array}{c}\text { slightly scruffy and } \\
\text { slightly dehydrated }\end{array}$ & darker red than normal, \\
2 & $\begin{array}{c}\text { scruffy, dehydrated, } \\
\text { decreased activity }\end{array}$ & several nodules, $<25 \%$ \\
3 & $\begin{array}{c}\text { scruffy, dehydrated, } \\
\text { decreased activity }\end{array}$ & consolidation \\
4 & numerous nodules \\
&
\end{tabular}

\subsection{Lung Histopathology}

Concurrent studies were evaluated for lung pathology without BAL using hematoxylin and eosin to define inflammation [16].

\subsection{Human Mesenchymal Stem Cells (hMSCs) and Bone Marrow Derived Macrophages (BMM)}

hMSCs were obtained from bone marrow aspirates of healthy volunteers after written and verbal informed consent. All procedures were approved by Case Western Reserve: (Case \# 12Z05)/University Hospitals \# 09-90195, Institutional Review Board through the Skeletal Research Center in collaboration with Dr. Arnold Caplan). hMSCs from the bone marrow of healthy volunteers were isolated, cultured and immunophenotyped as described previously [17]. hMSCs were used during log-growth [18]. BMMs were generated as previously described [15]. Briefly, hematopoietic progenitors were obtained from the femurs of $\mathrm{C} 57 \mathrm{BL} / 6 \mathrm{~J}$. Cells were grown in culture for 7 - 10 days in the presence of L929 spent medium. hMSCs and BMM were administered at $10^{6} / 100 \mu \mathrm{l}$ PBS through the retro-orbital sinus consistent with previous published observations of using this route of administration $[19,20]$.

\subsection{Macrophages for in Vitro Inflammation Studies}

C57BL/6 J or $C f t r^{\text {tm2Uth }}$ BMM was generated as described above [15]. Once a monolayer was generated and the cells were differentiated, the BMM were grown in the presence and absence of $0.5 \mu \mathrm{g} / \mathrm{ml}$ lipopolysaccharide to induce inflammatory cytokines TNF $\alpha$ and IL-6 in vitro. Stimulated BMM were cultured in vitro with or without the addition of supernatants derived from cultured hMSCs. After 24 hours, cells were harvested and evaluated for TNF $\alpha$ or IL- 6 gene expression based upon the changes in cytokine production in the mouse model post-hMSC administration [21]. The experiments were done with hMSC supernatants from 3-different donors and all measurements were done in triplicate.

\subsection{Human CF Epithelial Cells}

CF epithelial cells have been demonstrated to be hyper-responsive to bacterial exposure resulting in elevated production of IL-8 and IL-6 [22]. Many cell lines are available to study the CF airway epithelial cell inflammatory response. The studies outlined in this manuscript utilized immortalized cell lines developed by transforming human airway tracheal epithelial cells from a $\mathrm{CF}$ patient with adenovirus [23]. The immortalized CF cell line is called (IB3-1 cells), the control cells are the same $\mathrm{CF}$ derived tracheal epithelial cells transfected with adenovirus with full-length functional CFTR. These control cells are designated S9 (corrected) cells [23]. These cells were kindly provided by the laboratory of Dr. Pamela Davis (Case Western Reserve University, Cleveland, Ohio). Cells were maintained in a $5 \% \mathrm{CO}_{2}$ incubator at $37^{\circ} \mathrm{C}$ using LHC-8 media (Biosource, Camarillo, CA). All media contained penicillin/streptomycin and 10\% fetal bovine serum. The experiments were done at least 3- times with 3-different donors of 48 hour-cultured hMSC supernatants. After 24 hours, cells were harvested and evaluated for IL- 8 or IL- 6 based upon the changes in cytokine production in the mouse model post-hMSC administration [22].

\subsection{Bactericidal Assays}

Pseudomonas aeruginosa (PA M5715, a clinical isolate) was streaked on Tryptic Soy agarose (TSA) plates then inoculated into flasks [14]. PA M5715 was plated at dilutions of $10^{4}$ to $10^{7}$ to define the appropriate dilutions. Growth curve analysis and viability was used to define the CFUs. PA M5715 dilutions $\left(10^{4}\right.$ to $\left.10^{7}\right)$ were mixed 1:1 with either PBS, un-stimulated hMSC culture medium (US) or LPS-stimulated hMSC culture medium (LPS, $0.5 \mu \mathrm{g} / \mathrm{ml}$ for 24 hours) for 30 minutes at room temperature followed by plating on TSA plates and incubation overnight at $37.5^{\circ} \mathrm{C}$. Colony counts were quantitatively assessed at 24 hours.

\subsection{Cytokine Gene Expression}

Total RNA is extracted by RNAeasy protocol (Qiagen, Valencia, CA). Expression of mRNA is determined by real time RT-PCR using the ABI Prism 7000 Detection System (Applied Biosystems Inc., ABI, Foster City, CA). RNA specimens were analyzed in duplicate and normalized to GAPDH. Primers (TNF $\alpha$, IL- 6 , IL-8 for either mouse or human samples) were purchased from $\mathrm{ABI}$ and validated prior to studies.

\subsection{Chemotaxis Assays}

BAL derived alveolar macrophages (AM) and perito- 
neal neutrophils $(\mathrm{P})$ were evaluated for the ability to respond to MSC supernatants $(\mathrm{n}=3$ different donor derived supernatants, using transwells $(0.4 \mu \mathrm{M}$, Corning, NY). Both alveolar macrophages and neutrophils were obtained as previously described [15,24]. MSC supernatants were put into the lower chamber and cells were put into the upper chamber as previously described [25]. After 4 hours the numbers of cells in the upper chamber and the lower chamber were counted to reflect the ability to respond to MSC supernatant.

\subsection{Statistics}

Data were analyzed using quantitative and group comparisons with respect to measurements at individual time points. Data are described using means, standard deviations, and appropriate percentiles including medians and extreme values. Graphical representations show the data within different groups and at different time points. For group and time point comparisons, we used analysis of variance (ANOVA) or F values for variance between the means. For pair-wise comparisons non-parametric MannWhitney t-test or Wilcoxon signed-rank test were performed for samples with un-equal numbers or variance respectively, as indicated in the figure legend. Data of significance were established based upon an alpha value of $5 \%$ and below ( $\star \mathrm{P} \leq 0.05$ ). In some cases we designated alpha values which are not statistically significant as defined by our guidelines, however alpha values approaching $5 \%$ are indicative of how close to significance the data is, particularly when dealing with data that does not follow Gaussian distributions and is often found when dealing with in vivo studies. In this case we designate a specific $\mathrm{P}$ value with a $\operatorname{dot}(\bullet \mathrm{P}=0.07)$ instead of a star that is used for significance.

\section{RESULTS}

\section{1. hMSC Decreases Weight Loss and Lung Pathology Associated with Chronic Pseudomonas aeruginosa Infection}

Animals genetically modified to have altered expression of Cftr have been used extensively to study the pulmonary response to chronic infection with Pseudomonas aeruginosa. The benefits of the murine model are that it is a consistent, reproducible model of infection/ inflammation in the context of deficient $C f t r$ and normal mucocilliary clearance [26]. Our CF animal CORE Center has done extensive studies on the kinetics of the Cftr deficient lung response to pathogen exposure using a variety of murine $C f t r$ deficient models (14). The animals used in this study comprised a model that does not have severe gastrointestinal phenotype $\left(C f t r^{t m 2 U t h}\right)$ to explore the potential therapeutic application of hMSCs in resolving the pulmonary manifestations associated with chronic airway infection and inflammation in CF [27]. $\mathrm{Cftr}^{\text {tm2Uth }}$ mice and control animals were inoculated with Pseudomonas aeruginosa-laden agar beads with and without retro-orbital administration of $10^{6} \mathrm{hMSCs}$ or BMM and followed for either 3 or 10 days. Figure 1 shows the mean weight loss of $\mathrm{Cftr}^{\mathrm{tm} 2 \mathrm{Uth}}$ mice in response to Pseudomonas aeruginosa infection with and without treatment with $10^{6} \mathrm{hMSCs}$ or BMM. The mice were followed for 10 days with daily weights and clinical scores. At day 3, the Cftr ${ }^{\text {tm2Uth }}$ animals given Pseudomonas aeruginosa lost significant weight when compared to $\mathrm{C} 57 \mathrm{Bl} / 6$ mice given the same batch and dosing of Pseudomonas aeruginosa (Figure 1(a), $\mathrm{n}=3$ different experi-

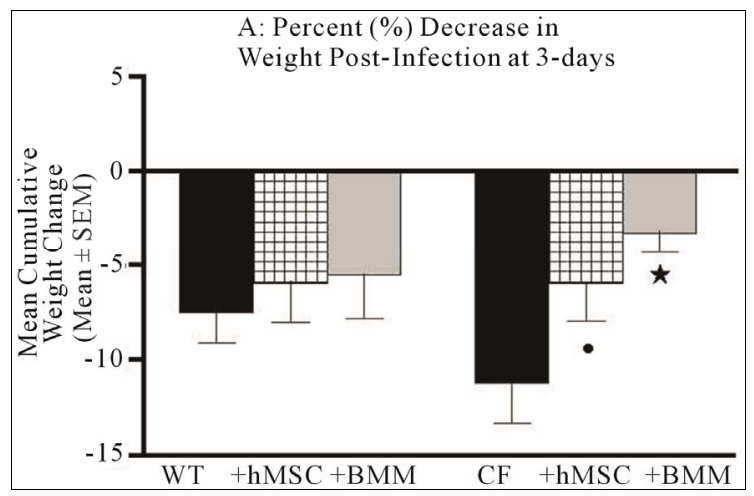

(a)

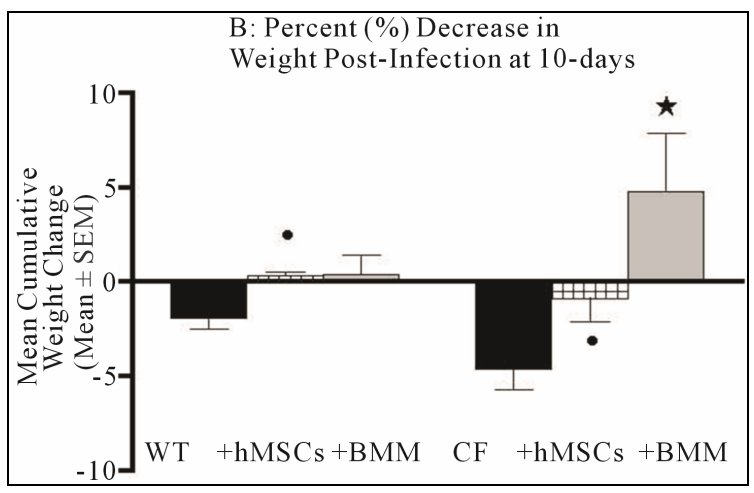

(b)

Figure 1. hMSCs Attenuate Weight Loss in the Chronic Infection/Inflammation Murine Model of CF. In each of the experiments $(\mathrm{n}=3$ different hMSC or BMM preparations), $\mathrm{Cftr}^{\text {tm2Uth }}$ and wild type littermate controls (5 - 8 animals/group/study at $16-24$ animals total per experiment) were infected with $5 \times 10^{5}$ CFUs of Pseudomonas aeruginosa (PA M5715) impregnated into agar beads. 24 hours post-infection, half of the mice were given $1 \times 10^{6} \mathrm{hMSCs}$ or BMM through the retro-orbital sinus. Animals were followed for either 3 or 10 days for weight loss. Treatment of WT and $C f t r^{t m 2 U t h}$ mice with hMSCs attenuated weight loss, with the $C f t r^{\text {tm } 2 U t h}$ mice reaching significance at both day 3 and day $10(\mathrm{P} \leq 0.05)$. Further, BMM treatment resulted in a statistical increase in weight $(P \leq 0.05)$ relative to the non-treated control at day 10 . We used the non-parametric Mann-Whitney t-test for the paired comparisons and the one-way ANOVA for the multiple comparisons. 
ments). Animals given $10^{6} \mathrm{hMSCs}$ or BMM retro-orbitally initially lost weight but by 3-day began to resolve the cachexia (Figure 1(a), n $=3$ different hMSC or BMM preparations, $\mathrm{P} \leq 0.05$ ). By day 10 , the $C f t r^{\text {tm } 2 U t h ~}$ mice treated with hMSCs had weights comparable to WT mice infected at the same time (Figure 1(b), $\mathrm{n}=3$ different hMSC preparations, $\mathrm{P} \leq 0.05)$. Treatment with BMM caused a statistical increase $(\mathrm{P} \leq 0.05)$ in weight gain over the WT controls and the Cftr ${ }^{\text {tm2Uth }}$ at day 10 consistent with the important role of myeloid cells in the CF lung response to infection (Bonfield, T.L., J. Leuk. Biol., 92: 1111-1122). Treatment of Cftr ${ }^{\text {tmlKth }}$ mice (delF508) with hMSCs also statistically decreased the amount of weight loss relative to the untreated infected control (Table 2) showing the consistency of the hMSC effect.

Weight loss is often used as a parameter in conjunction with clinical score as defined in Table 1. When the animals were assessed for clinical score, $C f t r^{t m 2 U t h}$ mice with infection but without hMSCs had a higher clinical score $(\mathrm{P} \leq 0.05)$ than controls which was attenuated with hMSCs even by 3 -days (the higher the value the sicker the animals, Figure 2(a), $\mathrm{P}=0.07$ ), suggesting a trend toward improvement. At day 10, there was a statistical difference between the WT and $C f t r^{\text {tm2Uth }}$ mice in terms of clinical score (Figure 2(b), $\mathrm{P} \leq 0.05$ ) which was significantly decreased by hMSC or BMM therapy $(\mathrm{P} \leq$ $0.05)$. The improvement in clinical score also reached significance in our $C f t r^{t m 1 K t h}$ mice (Table 2). When animals were sacrificed and evaluated for gross lung pathology (Figure 3), $C f t r^{\text {tm2Uth }}$ animals tended to have a greater focal lung consolidation and pathology scores compared to $\mathrm{C} 57 \mathrm{Bl} / 6 \mathrm{~J}$ controls (Figure 3, $\mathrm{P}=0.07$ ). Administration of the hMSCs statistically changed the pathology scores in the $C f t r^{\text {tm2Uth }}$ to have levels comparable with C57BL/6 mice infected with Pseudomonas aeruginosa $(\mathrm{P} \leq 0.05)$. Treatment of the Cftr ${ }^{\text {tm2Uth }}$ and WT mice with BMM had no statistical impact on lung pathology. Similar results were also found in the studies using $C f t r^{t m 1 K t h}$ mice (Table 2).

\section{2. hMSC Impact on Lung Inflammation}

In order to investigate how the hMSCs impact the mu-

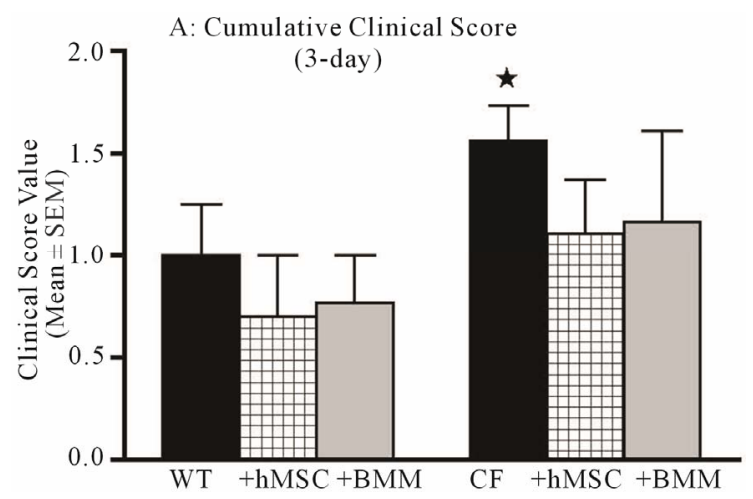

(a)

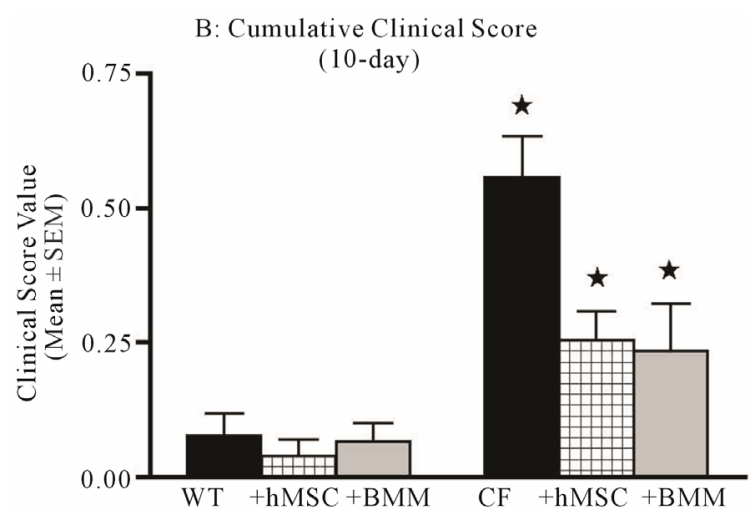

(b)

Figure 2. hMSCs decrease clinical score associated with chronic Pseudomonas aeruginosa Infection. Animals described in Figure 1 were followed for 10 days for clinical score (Table 1) and then euthanized. Data is expressed as cumulative clinical score at day 3 (a) and day 10 (b). Cftr $^{\text {tm } 2 \text { th }}$ mice had elevated clinical scores relative to WT mice at day 3 , it did not reach significance. $\mathrm{Cftr}^{\text {tm2Uth }}$ mice did have elevated clinical score at day 10 relative to WT mice infected at the same time $(\mathrm{P} \leq 0.05$, paired $\mathrm{t}$-test $)$. Administration of hMSCs and BMM resulted in a trend toward clinical improvement day $3((\mathrm{a}), \mathrm{P}=0.07)$ and reached significance at day $10((\mathrm{~b}), \mathrm{P} \leq 0.05)$ using one-way ANOVA analyses.

Table 2. MSCs in Pseudomonas aeruginosa infected Cftr $^{\text {tm1Kth }}$ (delF508) animals and controls.

\begin{tabular}{cccccc}
\hline Parameter & \multicolumn{2}{c}{ WT (C57BL/6 J controls) } & \multicolumn{2}{c}{${\text { Cftr }{ }^{\text {tm } 1 \text { Kth }} \text { (delF508) }}$} \\
\hline (Mean \pm SEM) & Sham control & MSCs & Sham control & MSC & P value \\
Mean Cumulative Weight Change & $-12.5 \pm 1.2$ & $-14.73 \pm 1.4$ & $-18.9 \pm 1.7$ & ${ }^{*}-13.3 \pm 1.9$ & $P \leq 0.03$ \\
Clinical score & $2.1 \pm 0.2$ & $2.1 \pm 0.1$ & $3.0 \pm 0.2$ & ${ }^{*} 2.1 \pm 0.2$ & $\mathrm{P} \leq 0.05$ \\
Gross Lung Pathology Score & $2.0 \pm 0.2$ & $1.7 \pm 0.2$ & $2.0 \pm 0.3$ & $1.7 \pm 0.2$ & \\
Total Absolute White Cell Count & $6.6 \times 10^{5} \pm 3.0 \times 10^{4}$ & $7.2 \times 10^{5} \pm 2.2 \times 10^{4}$ & $9.3 \times 10^{5} \pm 4.0 \times 10^{4}$ & ${ }^{*} 5.0 \times 10^{5} \pm 1.3 .0 \times 10^{4}$ & $\mathrm{P} \leq 0.05$ \\
Relative AMs & $18.7+3$ & $13.8+4$ & $9 \pm 3$ & ${ }^{*} 17 \pm 7$ & $\mathrm{P} \leq 0.05$ \\
Relative PMNs & $86 \pm 4$ & $81 \pm 3$ & $90 \pm 3$ & $82 \pm 7$ & \\
Bacteriology & $7.5 \times 10^{7} \pm 5.0 \times 10^{6}$ & $3.9 \times 10^{7} \pm 2.6 \times 10^{6}$ & $3.9 \times 10^{7} \pm 2.6 \times 10^{6}$ & ${ }^{*} 2.6 \times 10^{7} \pm 1.1 \times 10^{7}$ & $\mathrm{P} \leq 0.05$ \\
\hline
\end{tabular}


rine model of CF lung infection and inflammation, animals were euthanized followed by BAL for differentials, and total cell counts. As has been published previously, $C f t^{t m 2 U t h}$ animals had higher numbers of BAL leukocytes than WT mice given the same inoculums (Figure 4, $\mathrm{P} \leq$ 0.05). Cell based therapy, whether it was hMSCs or $\mathrm{BMM}$ resulted in a statistical decrease in the overall numbers of BAL leukocytes ( $\mathrm{P} \leq 0.05$, for BMM and hMSCs) in the $C f t r^{t m 2 U t h}$ mice which was not observed in the WT controls. The leukocyte recruitment in the $C f t r^{t m 2 U t h}$ showed decreased relative numbers of alveolar macrophages (Figure 5(a), $\mathrm{P} \leq 0.05$ ) and increased numbers of neutrophils (Figure 5, P $\leq 0.05$ ). Both hMSCs and BMM enhanced recruitment of alveolar macrophages (Figure 5(a), $\mathrm{P} \leq 0.05$ ) while attenuating the relative numbers of neutrophils (Figure 5(b), $\mathrm{P} \leq$

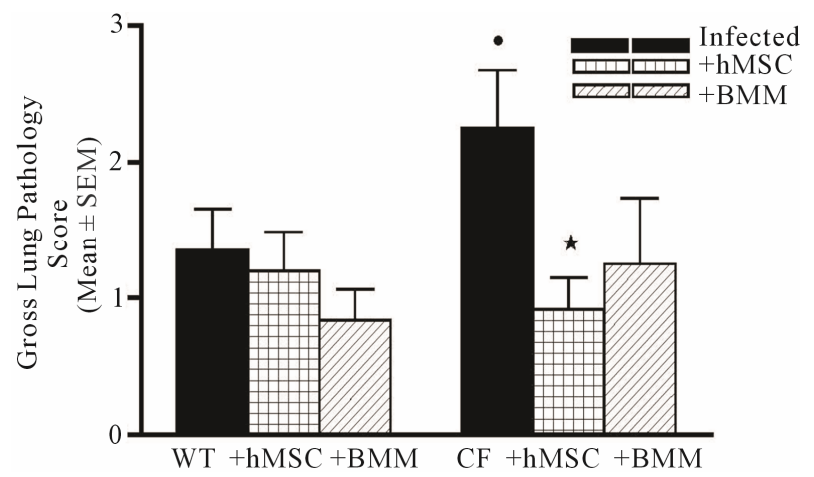

Figure 3. hMSCs decrease lung pathology associated with chronic Pseudomonas aeruginosa infection. Animals described in Figures 1 and 2 were also evaluated for lung pathology using the criteria outlined in Table 1. $\mathrm{Cftr}^{\text {tm2Uth }}$ mice tended to have higher gross lung pathology scores compared to WT mice $(\mathrm{P}=0.07)$. Treatment of $C f t r^{t m 2 U t h}$ mice with hMSCs resulted in significantly improved gross lung pathology $(\mathrm{P} \leq 0.05)$. BMM had no statistical impact on gross lung pathology. We used the non-parametric Mann-Whitney t-test for these analyses.

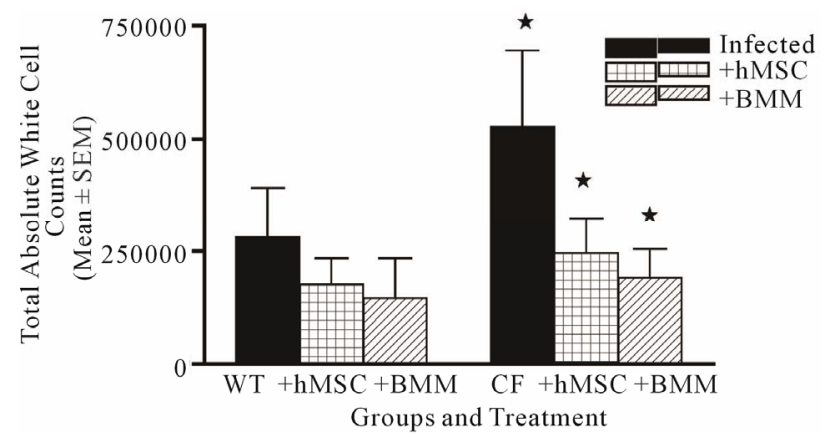

Figure 4. hMSC and cell recruitment into the lungs. Animals were euthanized and BAL was obtained for absolute white cell counts. Cftr ${ }^{\text {tm2Uth }}$ mice had elevated levels of leukocyte recruitment relative to WT mice $(\mathrm{P}=0.05)$ which was significantly decreased to levels approaching WT mice with the administration of either hMSCs or BMM $(\mathrm{P} \leq 0.05)$. We used the non-parametric Mann-Whitney t-test for these analyses.

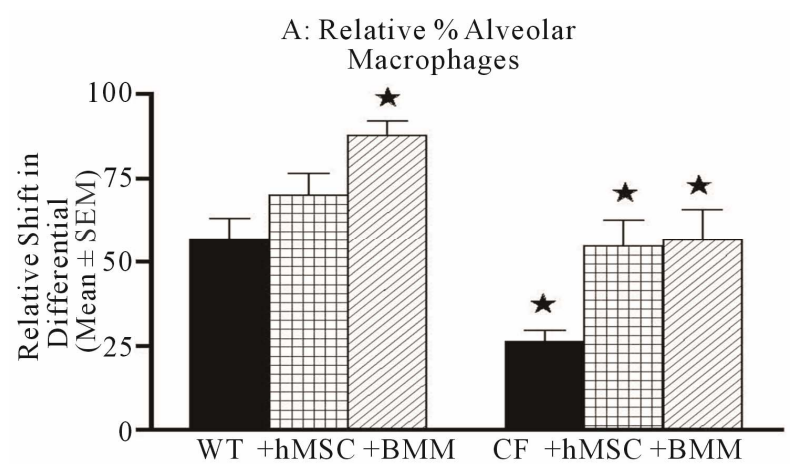

(a)

B: Relative \% PMNs

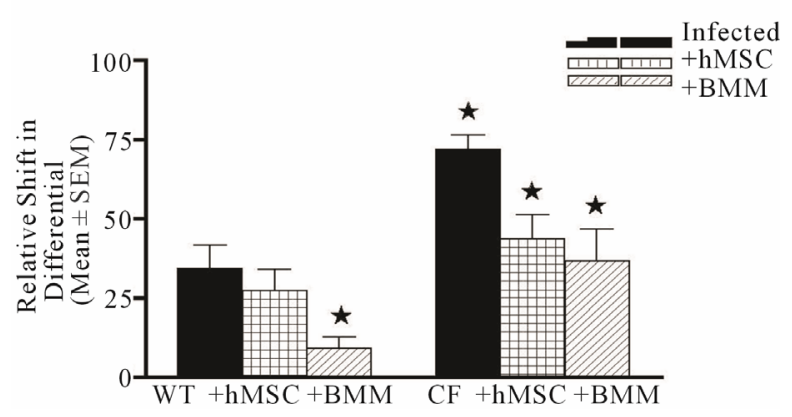

(b)

Figure 5. hMSCs decrease neutrophils while increasing Alveolar Macrophages. The BAL obtained from the in vivo studies was also evaluated for cellular differential. There was no difference in lymphocyte or eosinophil counts between the WT and $C f t r^{t m 2 U t h}$ with or without hMSC or BMM administration (data not shown). A Cftr ${ }^{\text {tm2Uth }}$ had elevated neutrophils ((b), $\mathrm{P} \leq 0.05)$ and decreased alveolar macrophages ((a), $\mathrm{P} \leq 0.05)$ relative to $\mathrm{WT}$ controls infected at the same time. Treatment of $\mathrm{Cftr}^{\text {tm2Uth }}$ mice with either hMSCs or BMM, resulted in increased alveolar macrophages $((\mathrm{a}), \mathrm{P} \leq 0.05)$, while decreasing neutrophil numbers $((b), P \leq 0.05)$. We used the non-parametric Mann-Whitney t-test for the paired comparisons and the one-way ANOVA for the multiple comparisons.

0.05). We obtained similar observations in the $C f t r^{t m 1 K t h}$ model (Table 2).

To determine if the hMSCs had the capacity to contribute to the shift in inflammatory cell recruitment away from neutrophils toward alveolar macrophages, chemotaxis studies were performed using alveolar macrophages and peritoneal neutrophils from WT and $C f t r^{t m 2 U t h}$ mice (Figure 6). There was no difference between WT and Cftr ${ }^{\text {tm2Uth }}$ (data not shown) neutrophils or alveolar macrophages when cultured with medium alone. Using three different hMSC derived supernatants, there was a significant chemotactic effect of the supernatants on recruiting $C f t r^{t m 2 U t h}$ alveolar macrophages but not on any other cell type $(\mathrm{P} \leq 0.05)$, with a suggestive suppressive effect on neutrophil recruitment. 


\section{3. hMSC Impact on the Cytokine Response in the in Vivo Murine Model of CF Airway Infection and Inflammation}

Cytokines are essential in the process of leukocyte recruitment and define the cell type and inflammatory response. We used Luminex multi-analyte technology to measure cytokines known to be involved in CF. KC, IL-6 and IL- $1 \beta$ were measured for chronic inflammation and neutrophil recruitment (Figure 7). MIP-2, resistin and adiponectin were measured due to their implications in regulating macrophage responses and inflammation [2830]. Not surprisingly, $C f t r^{t m 2 U t h}$ mice had elevated levels of KC (Figure 7(A)), IL-6 (Figure 7(B)), IL-1 $\beta$ (Figure 7(C)). Both KC and IL-6 levels were attenuated by both hMSC and BMM cell based therapy $(\mathrm{P} \leq 0.05)$. Only BMM attenuated the IL-1 $\beta$ levels (Figure 7(C), $\mathrm{P} \leq$ 0.05). $C f t r^{\text {tm2Uth }}$ mice had elevated BAL adiponectin levels (Figure (7D)) but not MIP-2 (Figure 7(E)) or resistin (Figure 7(F)) compared to infected WT controls. Only BMM attenuated MIP-2 and adiponectin concentrations $(\mathrm{P} \leq 0.05)$. Resistin concentrations are shown for comparison of a non-response. We did not detect IL-10 in any of the BAL samples (data not shown). Comparative studies in the $C f t r^{t m 1 K t h}$ mice are on-going and the focus of another manuscript.

\subsection{Mechanism of hMSC Anti-Inflammatory Activity}

To investigate the mechanisms behind the anti-in- flammatory impact of the hMSCs and whether it is related to hMSC soluble products, we used two different in vitro assays of cytokine production: LPS stimulation of bone marrow derived macrophages and epithelial cells. In the first set of studies we obtained bone marrow cells from WT and $C f t r^{t m 2 U t h}$ mice and differentiated them into

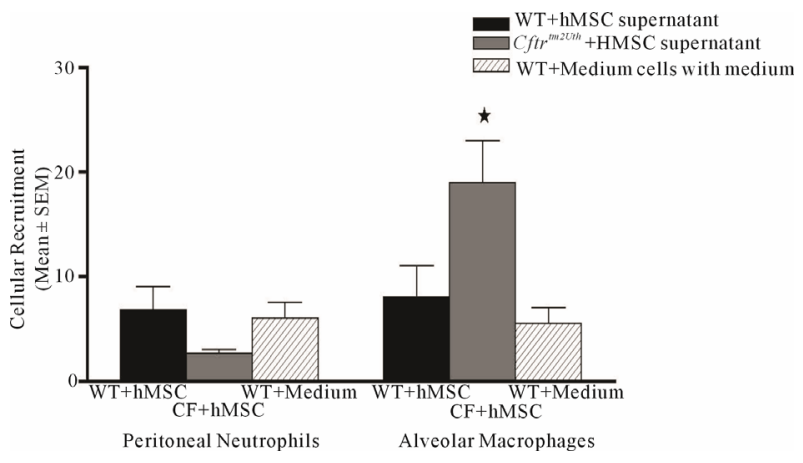

Figure 6. hMSC supernatants enhance macrophage recruitment. Alveolar macrophages and peritoneal neutrophils were obtained from WT and Cftr ${ }^{\text {tm2Uth }}$ mice and cultured in transwells $(0.4 \mu \mathrm{m})$ against three different batches of hMSCs supernatants compared to controls (WT or Cftr ${ }^{\text {tm2Uth }}$ cells with medium alone). Cellular recruitment was measured by counting the cells in the lower chamber after 4 hours incubation at $37^{\circ} \mathrm{C}$. There was no difference between WT and Cftr ${ }^{\text {tm } 2 \text { Uth }}$ cells cultured with control medium (only WT data is shown). Supernatant derived from hMSCs significantly recruitment $C f t r^{t m 2 U t h}$ alveolar macrophages relative to WT cells and controls $(\mathrm{P} \leq$ $0.05)$. Due to un-equal variance the Wilcoxon signed ranked test was used for these analyses.
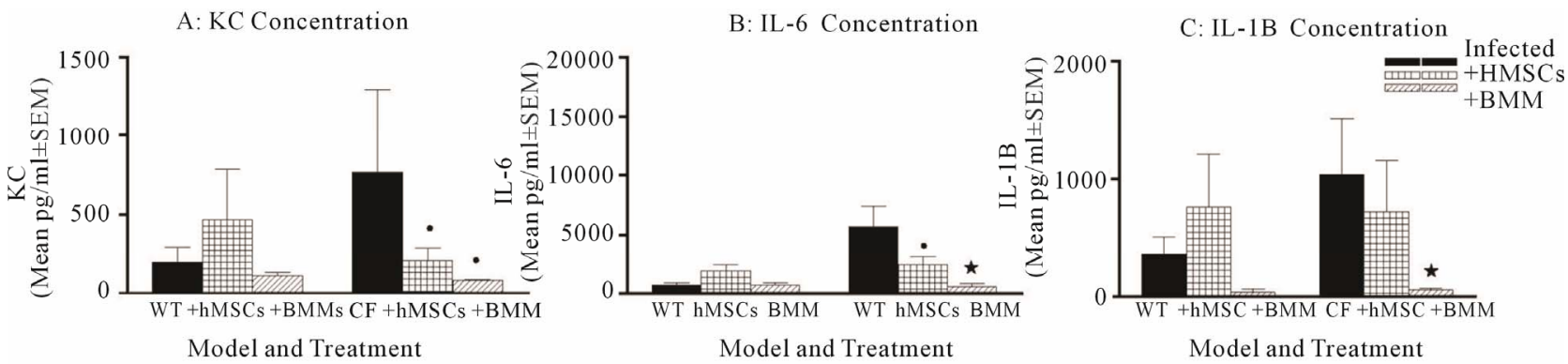

D: MIP-2 Concentration
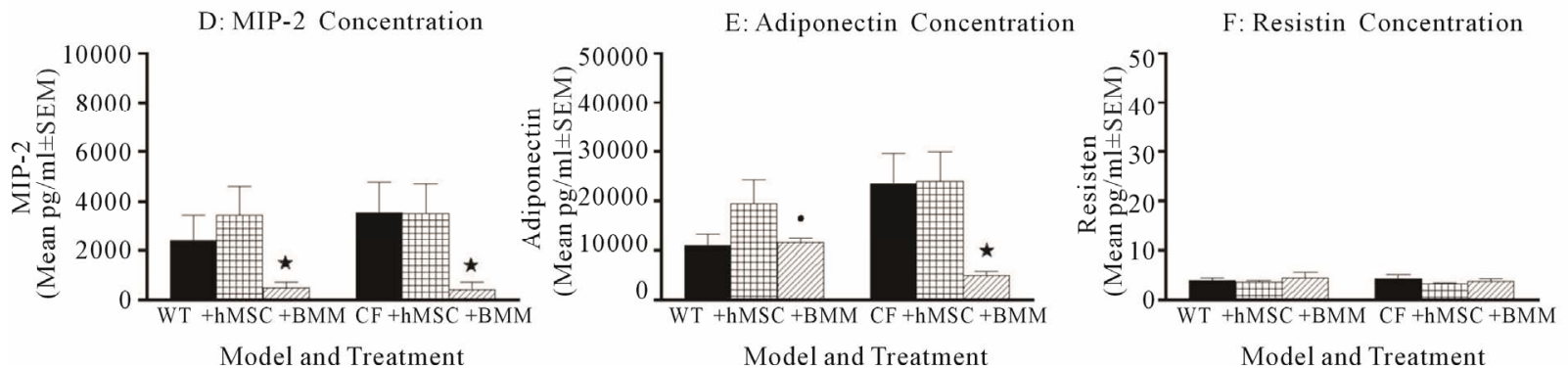

Figure 7. hMSCs shift cytokines away from neutrophil recruitment and pro-inflammation. Cftr ${ }^{\text {tm2Uth }}$ mice had elevated KC (A), IL-6 (B), IL-1B (C) MIP-2 (D), adiponectin (E) and resistin (F) concentrations relative to WT controls when comparing of variance the mean. hMSC and BMM administration decreased KC, IL-6 and IL-1B $(\mathrm{P} \leq 0.05, \mathrm{P}=0.07)$ with BMM giving a more dramatic effect $(\mathrm{P} \leq 0.05)$. BMM also decreased adiponectin and MIP-2 $(\mathrm{P} \leq 0.05)$. We used the non-parametric Mann-Whitney t-test for the paired comparisons and the one-way ANOVA for the multiple comparisons. 
bone marrow derived macrophages (BMM) in vitro. The WT and Cftr ${ }^{\text {tm2Uth }}$ BMM preparations were stimulated with $0.5 \mu \mathrm{g} / \mathrm{ml}$ LPS for 24 hours to induce the production of pro-inflammatory cytokines TNF $\alpha$ and IL- 6 mRNA expression. The LPS treated cultures were evaluated with or without the addition of hMSC supernatants to determine if hMSC soluble products could decrease the proinflammatory response to LPS in these in vitro cultures of BMM. We measured mouse IL-6, TNF- $\alpha$ mRNA expression and as predicted, LPS stimulated both IL-6 (Figure 8(a), $\mathrm{P} \leq 0.05$ ) and TNF $\alpha$ (Figure 8, $\mathrm{P} \leq 0.05$ ) with more being expressed by Cftr $^{\text {tm2Uth }}$ BMM. hMSC supernatants decreased both IL-6 (Figure 8(a), $\mathrm{P} \leq 0.05$ ) and TNF- $\alpha$ (Figure 8(b), $\mathrm{P}=0.07)$ mRNA expression.

Since primary epithelial cells are difficult to culture from CF and WT mice, we took advantage of established

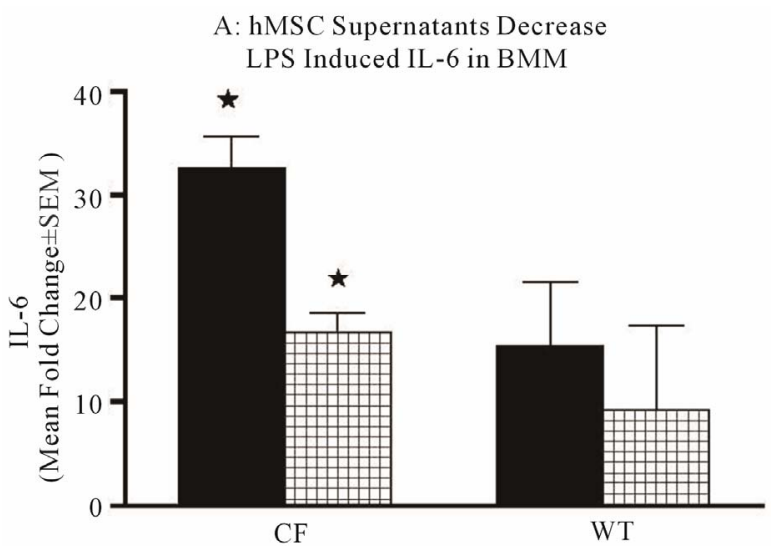

(a)

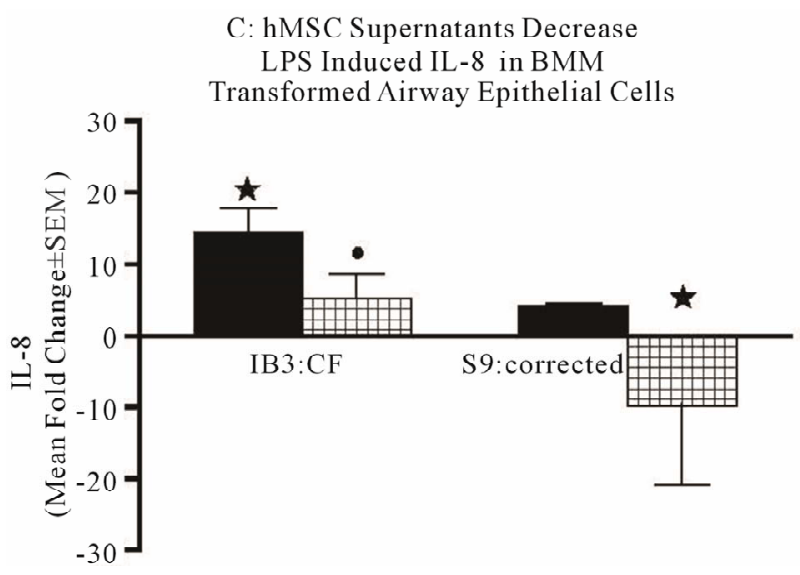

(c) human airway epithelial cell models of CF and controls (corrected; see description in the methods). LPS stimulation of the CF and corrtcted cells showed elevated IL-8 (Figure 8(c)) and IL-6 (Figure 8(d)) gene expression, again with the $\mathrm{CF}$ cells expressing significantly more of both cytokines $(\mathrm{P} \leq 0.05)$. hMSC supernatant suppressed both IL-8 and IL-6 mRNA expression $(\mathrm{P} \leq 0.05)$. These data suggest that soluble products produced by hMSC contribute to decreased cytokine production in both macrophages and epithelial cells. The mechanisms of this effect are the focus of our on-going studies.

\section{5. hMSCs and Anti-Bacterial Properties}

Recent literature has suggested that not only can hMSCs be anti-inflammatory, but they may also have

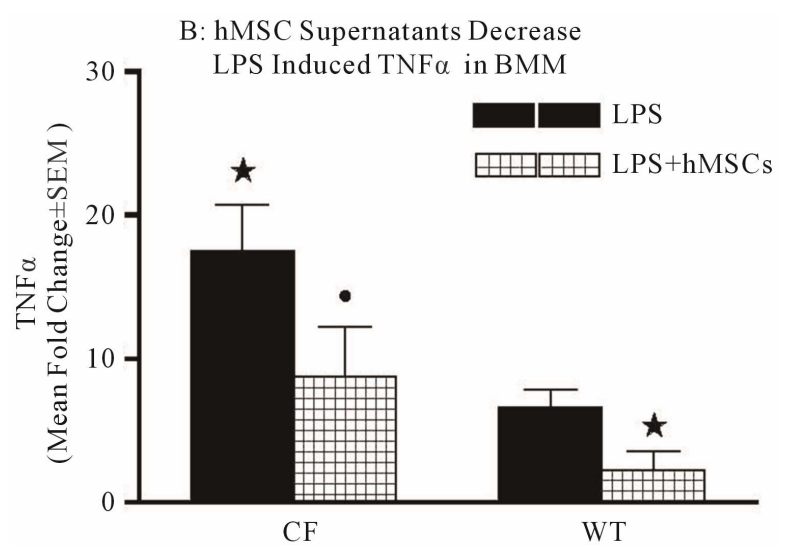

(b)

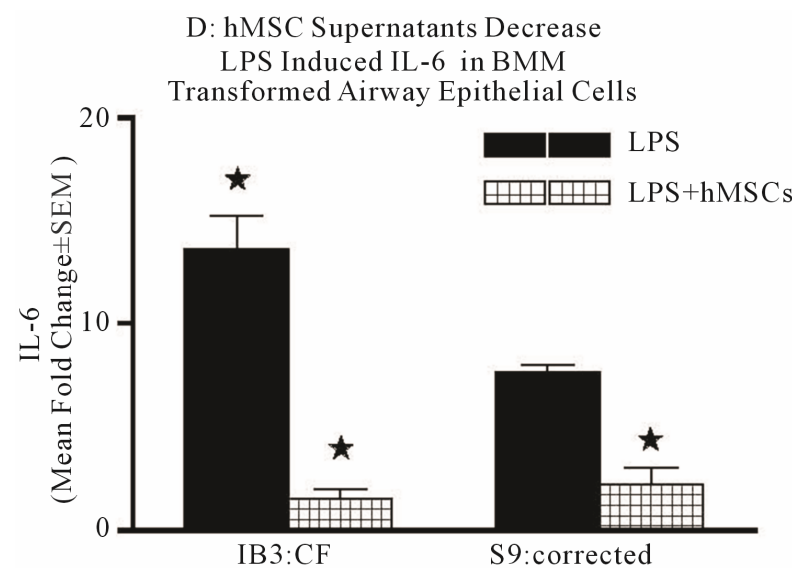

(d)

Figure 8. Mechanisms of anti-inflammation. Using in vitro modeling with BMM from Cftr ${ }^{\text {tm2Uth }}$ and WT mice we measured changes in LPS induced IL-6 (a) and TNF $\alpha$ (b) when cultured in the presence or absence of hMSC derived supernatants. $C f t r^{t m 2 U t h}$ expressed greater levels of both IL- 6 and TNF $\alpha$ mRNA post-stimulation with LPS (Figures 8(a) and (b) respectively, $\mathrm{P} \leq 0.05, \mathrm{n}=$ 3 different hMSC preparations). WT bone marrow cells expressed comparable levels of IL- 6 and TNF $\alpha$ mRNA regardless of co-culture conditions (with or without hMSC supernatants). In panels C and D, transformed human tracheal epithelial cells from a CF patient (IB3) and the corrected control corrected (S9) were also cultured with LPS in the presence and absence of hMSC supernatant and evaluated for IL-8 (c) and IL-6 (d) mRNA. LPS significantly induced epithelial IL-8 (P $\leq 0.05)$ and IL-6 (P $\leq 0.05)$ mRNA expression relative to the controls. Like the BMM derived cells, supernatants derived from hMSCs significantly decreased IL-6 and IL-8 mRNA synthesis in response to exposure to LPS (P $\leq 0.05, \mathrm{n}=3$ different hMSC preparations). The students' t-test was used for these analyses. 
anti-bacterial potential [5,31]. We evaluated the colony forming units of Pseudomonas aeruginosa remaining in the lungs of the $C f t r^{t m 2 U t h}$ at day 3 to test this function in our in vivo model. Whole lung homogenates were made of the animals and cultured overnight on TSA plates. Both WT and CF animals had significant and comparable bacterial loads at day 3 (Figure 9(a)). CF animals treated with hMSCs or BMM, had significantly less bacterial counts (Figure 9(a), $\mathrm{P} \leq 0.05$ ), than the animals infected at the same time but without cell based therapy. These observations were consistent in our $C f t r^{\text {tm } 1 \text { Kth }}$ animal studies (Table 2).

To determine if this was a direct effect of the hMSCs, supernatants from hMSCs were cultured with Pseudo-

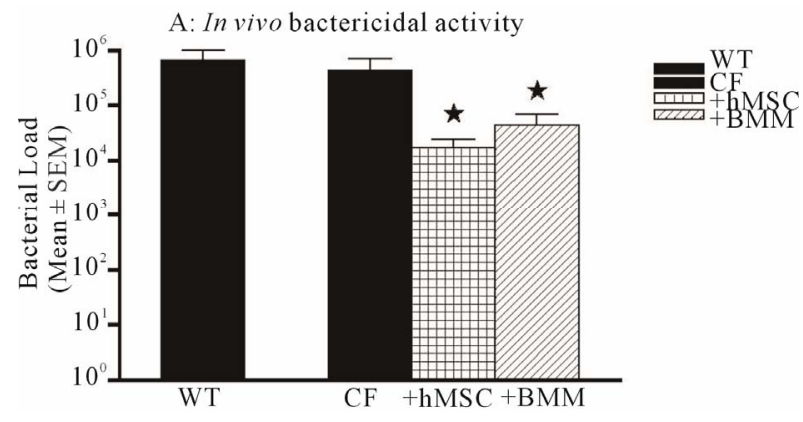

(a)

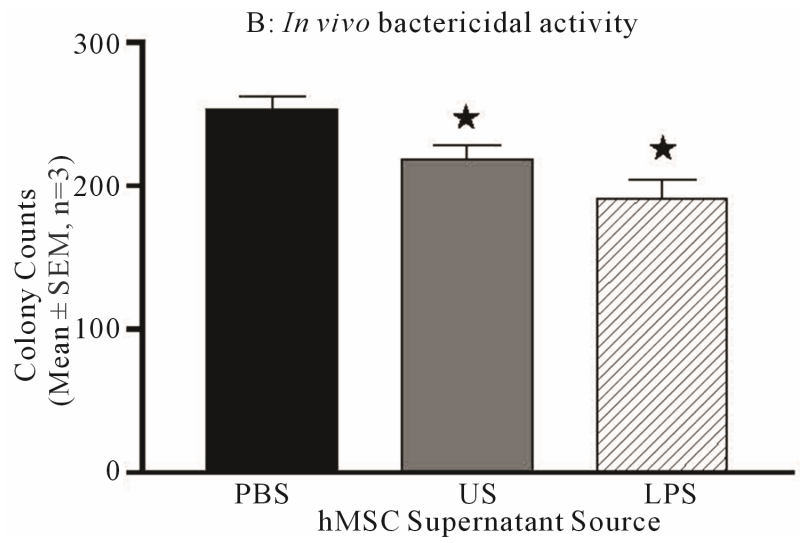

(b)

Figure 9. hMSC bactericidal activity. Whole lung homogenates and BAL fluid were obtained from the in vivo models and evaluated for bacterial load (colony forming units). Both WT and $C f t r^{\text {tm2Uth }}$ mice had elevated and comparable CFUs postInfection at day 3. The level of CFUs were significantly decreased by the administration of both hMSCs and WT BMM ((a), $\mathrm{P} \leq 0.05$, for $\mathrm{n}=3$ different $\mathrm{hMSC}$ and BMM preparations). To determine if this decrease in bacterial load was due to hMSC products or host response, hMSC supernatants were cultured with Pseudomonas aeruginosa ( $\left.10^{4} \mathrm{CFU}\right)$. Supernatants were used from un-stimulated hMSCs (cultured in plastic) or hMSCs stimulated for 24 hours with LPS $(0.5 \mu \mathrm{g} / \mathrm{ml})$. Supernatants from the hMSCs significantly decreased bacterial CFUs ((b), $\mathrm{n}=3$ different hMSC derived supernatants, $\mathrm{P} \leq$ 0.05). We used the non-parametric Mann-Whitney t-test for these analyses. monas aeruginosa in vitro. The supernatants were derived from hMSCs with or without stimulation with LPS (0.5 $\mu \mathrm{g} / \mathrm{ml}$ for 24 hours) to determine if the hMSCs would generate products with enhanced bactericidal activity in response to endotoxin. The Pseudomonas aeruginosa was cultured with the different hMSC supernatants and then plated out on TSA plates and allowed to grow overnight. Bacterial counts were evaluated and compared to controls of bacteria not treated or treated with PBS. The hMSC supernatant obtained from nonstimulated hMSCs (US) and LPS-stimulated hMSC (LPS) culture supernatant significantly decreased the ability of the bacteria to grow in vitro (Figure 9(b), $\mathrm{P} \leq 0.05$ ) over the PBS control. BMM supernatants also decreased bacterial load in vitro (data not shown), but is the focus of a separate manuscript.

To identify the potential agent associated with the anti-inflammatory and anti-bacterial properties of hMSC supernatants, we evaluated the BAL supernatants from both $\mathrm{Cftr}^{\text {tm2Uth }}$ and $\mathrm{Cftr}^{\text {tm1Kth }}$ (data not shown) and controls for the presence of LL-37, because it has been reported to be both anti-inflammatory and anti-microbial $[5,31,32]$. BAL fluid was obtained from mice chronically infected with Pseudomonas aeruginosa with and without hMSC or BMM therapy (Figure 10, $\mathrm{n}=3$ experiments with 4-6 BAL samples/group). All of the BAL fluid had detectable levels of LL-37, with the highest levels found in the Cftr deficient animals treated with hMSCs $(\mathrm{P} \leq 0.05)$ using the F-test for analysis of variance, $\mathrm{P}=0.07$ for the Mann-Whitney t-test). The trend of increased levels of LL-37 in both Cftr deficient models supports the potential role of LL-37 in the effectiveness of hMSCs at de-

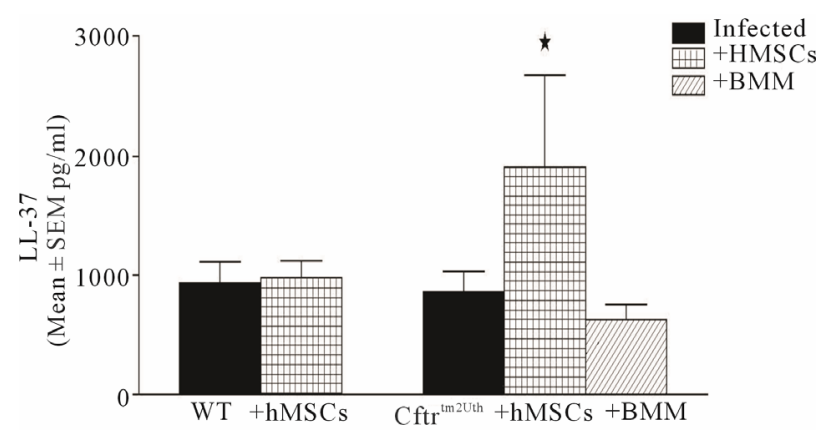

Figure 10. $C f t r^{t m 2 U t h}$ and WT mice BAL have elevated LL-37 post-hMSCs administration. Cftr ${ }^{\text {tm } 2 U t h}$ and WT mice were chronically infected with Pseudomonas aeruginosa with and without either hMSC or BMM therapy and followed for 10 days. Animals were euthanized with BAL. BAL was evaluated for LL-37 using an ELISA based methodology. Cftr ${ }^{\text {tm2Uth }}$ mice and WT mice had comparable levels of LL-37, administration of hMSCs but not BMM increased LL-37 ( $\mathrm{n}=3$ different studies; 4 - 6 samples/group, $\mathrm{P} \leq 0.05$ ). We used the F-test to compare variances between $C f t r^{t m 2 U t h}$ with and without MSCs along with like treated controls. The Mann-Whitney t-test value was $\mathrm{P}$ $=0.07$. 
creasing bacterial load and inflammation. Although the BMM had anti-inflammatory and anti-microbial effects in vivo, they did not appear to associated with LL-37 levels, suggesting the involvement of other anti-microbial proteins besides LL-37 maybe important in the antimicrobial effects of BMM. This is the focus of on-going studies in our laboratory.

\subsection{Potential Sources of hMSCs in Vivo}

With differences in LL-37 concentrations in the in vivo model, we investigated the potential source of the LL-37. hMSCs cultured in vitro for 24 hours secreted LL-37 (Figure 11). LPS stimulation for 24 hours did not appear to significantly change the amount of secreted LL-37 relative to the un-stimulated control. Incubation of the hMSCs with the CFTR inhibitor I-172 $(10 \mu \mathrm{g} / \mathrm{ml}$ for 48 hours), significantly reduced the ability of hMSCs to secrete LL-37 relative to the un-stimulated control $(\mathrm{P} \leq$ 0.05). Further, when cells were stimulated with LPS after inhibiting CFTR activity (for 48 hours), the amount of LL-37 was even further suppressed relative to the LPS control $(\mathrm{P} \leq 0.05)$. These data suggest that the hMSCs express functional CFTR and that blocking CFTR impacts the ability to produce LL-37 and the ability to respond to LPS. To determine if CF MSCs express CFTR to validate the I-172 studies, we took advantage of an immortal-mouse derived MSC clone BMC9 [33], especially since we have a highly reproducible mouse $C f t r$ gene expression assay in our CF animal CORE center [26,34]. These cells are abundant and have a MSC

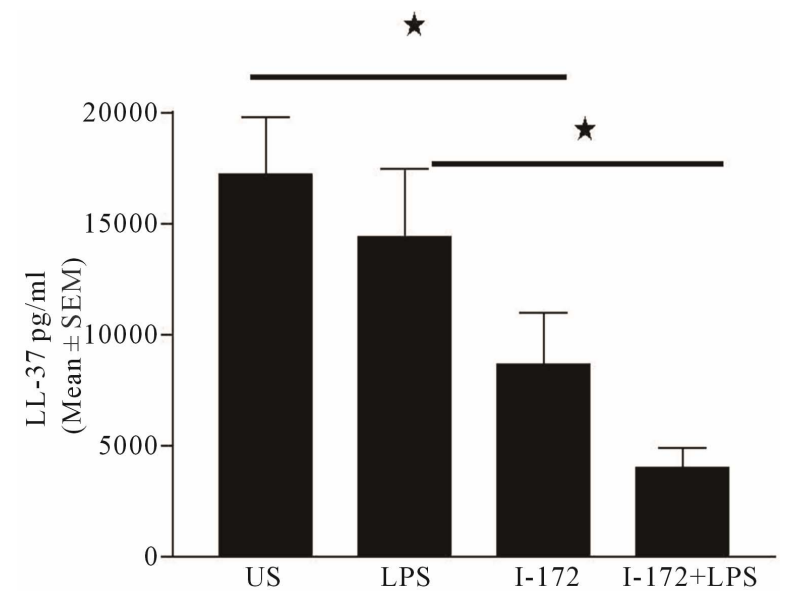

Figure 11. hMSCs and BMM cells secrete LL-37. hMSCs utilized in the animal models were cultured in vitro with and without the addition of $0.5 \mu \mathrm{g} / \mathrm{ml}$ LPS ( $\mathrm{n}=5$ preparations) with or without inhibition of CFTR with I-172 $(10 \mathrm{ug} / \mathrm{ml}$ for 48 hours) and incubated for 24 hours. The supernatants were harvested and evaluated for LL-37 concentration. hMSCs secreted LL-37 with and without LPS stimulation. Inhibition of CFTR function significantly inhibited LL-37 secretion by hMSCs with or without LPS stimulation $(\mathrm{P} \leq 0.05)$. We used the student t-test for these analyses. phenotype when grown at $37^{\circ} \mathrm{C}$. Our data showed that the BMC9 cells have $0.36 \% \pm 0.14 \%$ Cftr expression $(\mathrm{Ct}$ value of $31 \pm 1)$ compared to intestinal epithelium $(\mathrm{Ct}$ value around $20 \pm 3$ ), which expresses extremely high levels of $C f t r$. The sensitivity and specificity of our $C f t r$ expression assay is $40 \pm 2 \mathrm{Ct}$. If we had used a lower expressing tissue, the \% of Cftr levels would be higher. BMC9 cells cultured with I-172 $(10 \mu \mathrm{g} / \mathrm{ml}$, for 48 hours $)$ secreted 37\% \pm 13\% (Mean \pm SEM, $n=3$ ) less LL-37 than BMC9 cells not cultured with $\mathrm{I}-172(\mathrm{P} \leq 0.05)$. These data suggest that MSCs express CFTR and that CFTR function impacts the ability of MSCs to produce products such as LL-37. Our future studies are aimed at studying the differences between and Cftr deficient MSCs and control MSCs.

\section{DISCUSSION}

This investigation focused on hMSCs as a potential anti-inflammatory and anti-bacterial therapeutic intervention in $\mathrm{CF}$, due to their ability to evade immune-surveillance. We show for the first time that in an in vivo model mimicking lung infection and inflammation in $\mathrm{CF}$, retro-orbital administration of hMSCs attenuated weight loss, clinical score and lung pathology associated with chronic infection with Pseudomonas aeruginosa. Besides the benefits in attenuating wasting and overall sickliness of the animals, mechanistically there was a shift in the differential away from neutrophils recruitment to a predominance of alveolar macrophages. The shift in the pulmonary cell type potentially related to changes in the BAL levels of KC, IL- $1 \beta$ and IL- 6 . Further, hMSC administration resulted in significant improvement in infection resolution in vivo. Mechanistically, we show that both the anti-bacterial and anti-inflammatory components of the hMSCs were due to products secreted from the hMSCs, including LL-37. We also show that hMSC soluble products can alter cellular recruitment in vitro as well as in vivo. Further, the data suggests that MSCs express CFTR and are functionally impacted by CFTR activity, decreasing LL-37 production in response to LPS stimulation. An additional observation in these studies is the surprising improvement in several of the infection model outcomes by the administration of BMM, implying the important role of these cells in the pathophysiology of CF and their potential for correction in vivo. These studies highlight for the first time the exciting potential of using cell based therapy to treat infection and inflammation in CF.

$\mathrm{CF}$ is a debilitating disease which results in defective function or expression of CFTR [2,35]. This is a chloride channel receptor which is essential for maintaining the electrical potential/ion balance across epithelial cell barriers [36]. The disease affects all endocrine organs, and 
medical treatments have been developed to manage most of the anomalies associated with the genetic defect. However, little progress has been made in terms of improving quality of life and life expectancy for patients with CF as they progress into pulmonary complications associated with infection and inflammation [36]. One of the major components of CF lung disease is the susceptibility of these patients to lung infection with Pseudomonas aeruginosa [37], sometimes as early as 2 years of age. The pathogen in the CF lung acquires a unique phenotype which decreases the efficiency of innate immune mechanisms aimed at resolution [38]. The second component of CF lung disease is the overt and robust inflammatory response which is consistent throughout the life of a CF patient primarily associated with bacterial colonization [39]. Clinical trials of anti-inflammatory products such as ibuprofen and pioglitazone have been utilized to address the inflammatory components of this disease [40]. Animal models such as the Cftr deficient pig [41] and the Cftr deficient mouse [27] have been used to study the issues of Pseudomonas aeruginosa pathogenesis and the inflammatory response to infection. In the studies described in this manuscript, we used the Cftr-deficient murine models R117H (class IV mutant), delF508 (class II mutant) and their respective controls $[26,27]$, because of the availability and the proof of concept nature of this manuscript.

Bone marrow transplantation studies in which $\mathrm{CF} \mathrm{KO}$ mice were transplanted with WT bone marrow cells showed decrease in the inflammatory response to infection with Pseudomonas aeruginosa $[11,42]$. hMSCs have been shown to decrease inflammation in bone repair [10] as well as attenuation of inflammation in both the acute and chronic ovalbumin murine models of asthma $[43,44]$. The studies reported in this manuscript show that hMSCs and BMM given retro-orbitally were efficient at attenuating infection and inflammation. These data are supportive of other studies [45-47] showing not only anti-bacterial activity, but as a potential candidate for anti-inflammatory therapy [5]. In terms of the anti-inflammatory response, we did not detect IL-10 in the BAL, which a potential candidate for an anti-inflammatory action [48]. This might be due to the fact that CF mice typically have decreased levels of IL-10, thought to be a product of the $C f t r$ defect itself $[49,50]$. TGF- $\beta$ would be another likely candidate, which is the focus of on-going work [51,52]. The ability to shift the inflammatory filtrate away from elevated $\mathrm{KC}$ (neutrophil recruitment), IL-1 $\beta$ and IL-6 (chronic pro-inflammatory cytokines) is also a finding that may be important in the mechanistic contribution of the hMSCs on the CF lung milieu. Further, the chemotaxis studies suggest that the hMSCs have the capacity to direct cellular recruitment in a cell type and phenotype specific manner.

Bacterial infection with pathogens, like Pseudomonas aeruginosa contribute to the lung pathophysiology in $\mathrm{CF}$. The challenge clinically, is trying to attenuate the inflammation that damages the lung structure $[1,40]$ while at the same time not increasing the susceptibility to colonization with pathogens. In our studies we show that not only are the hMSCs and wild type BMM anti-inflammatory, they also improve the ability to resolve infection in our model of chronic Pseudomonas aeruginosa infection. To begin to focus on a potential candidate for the anti-inflammatory and microbicidal activity, we evaluated whether the antimicrobial peptide LL-37 was involved. This is based upon recent data that hMSCs produce LL-37 and that they can resolve infection in scenarios of bacterial induced acute lung injury [5,53]. Our studies are the first to use $\mathrm{Cftr}^{\text {tm2Uth }}$ CFTR deficient animals, to study the production of LL-37 [48,54]. We show that both WT and Cftr ${ }^{\text {tm } 2 \text { Uth }}$ mice produce similar levels of LL-37 in response to chronic infection with Pseudomonas aeruginosa. This is consistent with studies focusing of CF LL-37 mRNA production [55]. The inability of LL-37 to be efficient at attenuating inflammation and infection in the CF lung, maybe due to neutralization by LPS [32,56], degradation by neutrophil elastase $[57,58]$ or binding to DNA complexes [59]. All of these components of the CF lung milieu have been shown to block endogenous LL-37 activity. In our studies, we show that hMSC treatment increased LL-37 production which may aide enhancing resolution of bacterial infection. The production of LL-37 by the hMSCs may be able to overcome the LL-37 blocking and neutralization CF lung milieu. BMM treatment did not impact BAL levels of LL-37, suggesting alternative mechanisms for the antimicrobial effect which may also be part of the hMSC antimicrobial actions and the focus of on-going studies in our laboratory. Our future studies will focus on the mechanisms of hMSCs and BMM anti-microbial activity and the impact on lung pathophysiology using our in vivo models of chronic Pseudomonas aeruginosa infection.

Another important observations gained from these studies is the surprising impact of BMM on the outcome of the animals chronically infected with Pseudomonas aeruginosa. In our previous studies, BMM were used as a control and had no-impact on disease progression in either an acute or chronic murine model of asthma $[43,44]$. In these studies, focusing on infection induced inflammation in the $\mathrm{Cftr}^{\text {tm2Uth }}$ mice and controls, the BMM also contributed to beneficial outcomes in the $\mathrm{CF}$ infection model. In these studies, $C f t{ }^{t m 2 U t h}$ mice were not irradiated, but were given WT BMM through retro-orbital administration. The animals which received the WT BMM did better with decreased neutrophils and cyto- 
kines like the hMSCs as well as improved the ability to resolve infection, without the need for irradiation or immunosuppression. These studies compliment previous observations that irradiated Cftr $\mathrm{KO}$ animals given WT bone marrow had decreased inflammation and improved ability to resolve infection relative to non-treated irradiated controls [60]. These observations imply that myeloid cells such as macrophages and bone marrow derived cells such as MSCs may play important roles in the pathophysiology of $\mathrm{CF}$ and that therapeutic intervention with WT cells or corrected CF cells may provide an alternative direction for therapy. This was an un-expected observation since in previous models BMM had no effect on the disease out-come although the disease focus was inflammation associated with asthma not infection with Pseudomonas aeruginosa $[43,44]$. We have recently published studies suggesting that myeloid cells are important in the CF response to infection, supporting the potential of BMM derived cell based therapy in CF [24]. Other studies have used murine fibroblast cells (3T3 cells), which are not exactly the correct control relative to the Cftr $^{\text {tm2Uth }}$ haplotype and ultimately the murine source $[12,61]$ since we are using bone marrow derived cells from humans for MSCs and bone marrow derived macrophages from congenic mice. MSCs are immunoprivaledged and to date no adverse events have been established in the context of on-going clinical trials (CLINICALTRIAL@NIH.GOV). Although the alternative control cell therapy for BMM and hMSCs is on-going in our laboratory, the absence of the additional controls does not take away from the significant implications of our studies for investigating cell based therapy in CF. Further, our future studies will focus on the difference between WT and Cftr ${ }^{\text {tm2Uth }}$ BMM, and whether bone marrow correction is also a potential therapeutic direction.

These studies provide a proof of concept for exploring the potential of hMSC and BMM infusions in CF in the context of pulmonary infection with Pseudomonas aeruginosa. Since hMSCs have been shown to be "immuno-privileged" in the context of rejection, they may provide an alternative therapeutic for patients with CF. It is clear that once hMSCs reach their destined milieu, they have the capacity to change the milieu as well as the overall phenotype of the cells at the milieu interface. Future studies will involve investigating the mechanistic role of hMSCs in attenuating both the bacterial load and the lung inflammatory phenotype in the CF lung. The implication that BMM may also provide an alternative mode of therapeutic intervention suggests options for autologous bone marrow derived immune cell correction using induced pluripotent stem cells or transfection to enhance the ability of CF patients to manage pathogen insult and the inflammatory response.

\section{ACKNOWLEDGEMENTS}

We thank the Case Western Reserve University CF animal CORE and the CF Inflammatory Mediator CORE for their assistance in using the animal models and the values of quantitative PCR and Luminex multianalyte bead-arrays. This work was funded by the David and Virginia Baldwin Fund (AIC) and the Case Western Reserve Vision Fund (TLB), R21 HL109699 (TLB), National Center of Regenerative Medicine (TLB) and P01-DE019759 (AW), Cystic Fibrosis Foundation, Fellowship Grant DMARI12DO (AMD)

\section{REFERENCES}

[1] Nichols, D.P., Konstan, M.W. and Chmiel, J. F. (2008) Anti-inflammatory therapies for cystic fibrosis-related lung disease. Clinical Reviews in Allergy \& Immunology, 35, 135-153. doi:10.1007/s12016-008-8081-2

[2] Chmiel, J.F. and Konstan, M.W. (2007) Inflammation and anti-inflammatory therapies for cystic fibrosis. Clinics in Chest Medicine, 28, 331-346. doi:10.1016/j.ccm.2007.02.002

[3] Mayer-Hamblett, N., Aitken, M.L., Accurso, F.J., Kronmal, R.A., Konstan, M.W., Burns, J.L., Sagel, S.D. and Ramsey, B.W. (2007) Association between pulmonary function and sputum biomarkers in cystic fibrosis. American Journal of Respiratory and Critical Care Medicine, 175, 822-828. doi:10.1164/rccm.200609-1354OC

[4] Caplan, A.I. (2009) Why are MSCs therapeutic? New data: New insight. The Journal of Pathology, 217, 318324. doi:10.1002/path. 2469

[5] Krasnodembskaya, A., Song, Y., Fang, X., Gupta, N., Serikov, V., Lee, J.W. and Matthay, M.A. (2010) Antibacterial effect of human mesenchymal stem cells is mediated in part from secretion of the antimicrobial peptide LL-37. Stem Cells, 28, 2229-2238. doi:10.1002/stem.544

[6] Caplan, A.I. (2007) Adult mesenchymal stem cells for tissue engineering versus regenerative medicine. Journal of Cellular Physiology, 213, 341-347. doi: $10.1002 /$ jep. 21200

[7] Dennis, J.E. and Caplan, A.I. (1996) Analysis of the developmental potential of conditionally immortal marrow-derived mesenchymal progenitor cells isolated from the $\mathrm{H}-2 \mathrm{~Kb}$-tsA58 transgenic mouse. Connective Tissue Research, 35, 93-99. doi:10.3109/03008209609029179

[8] Abdallah, B.M. and Kassem, M. (2007) Human mesenchymal stem cells: From basic biology to clinical applications. Gene Therapy, 15, 109-115. doi:10.1038/sj.gt.3303067

[9] Caplan, A.I. and Dennis, J.E. (2006) Mesenchymal stem cells as trophic mediators. Journal of Cellular Biochemistry, 98, 1076-1084. doi:10.1002/jcb.20886

[10] Dennis, J.E., Cohen, N., Goldberg, V.M. and Caplan, A.I. (2004) Targeted delivery of progenitor cells for cartilage repair. Journal of Orthopaedic Research, 22, 735-741. doi:10.1016/j.orthres.2003.12.002

[11] Bruscia, E.M., Zhang, P.X., Ferreira, E., Caputo, C., Em- 
erson, J.W., Tuck, D., Krause, D.S. and Egan, M.E. (2009) Macrophages directly contribute to the exaggerated inflammatory response in cystic fibrosis transmembrane conductance regulator ${ }^{-/-}$mice. American Journal of Respiratory Cell and Molecular Biology, 40, 295-304. doi:10.1165/rcmb.2008-01700C

[12] Weiss, D.J., Berberich, M.A., Borok, Z., Gail, D.B., Kolls, J.K., Penland, C. and Prockop, D.J. (2006) Adult stem cells, lung biology, and lung disease. NHLBI/Cystic Fibrosis Foundation Workshop. Proceedings of the American Thoracic Society, 3, 193-207. doi:10.1513/pats.200601-013MS

[13] Van Heeckeren, A.M., Schluchter, M.D., Xue, W. and Davis, P.B. (2006) Response to acute lung infection with mucoid Pseudomonas aeruginosa in cystic fibrosis mice. American Journal of Respiratory and Critical Care Medicine, 173, 288-296. doi:10.1164/rccm.200506-9170C

[14] Van Heeckeren, A.M., Tscheikuna, J., Walenga, R.W., Konstan, M.W., Davis, P.B., Erokwu, B., Haxhiu, M.A. and Ferkol, T.W. (2000) Effect of Pseudomonas infection on weight loss, lung mechanics, and cytokines in mice. American Journal of Respiratory and Critical Care Medicine, 161, 271-279. doi:10.1164/ajrccm.161.1.9903019

[15] Bonfield, T.L., Thomassen, M.J., Farver, C.F., Abraham, S., Koloze, M.T., Zhang, X., Mosser, D.M. and Culver, D.A. (2008) Peroxisome proliferator-activated receptorgamma regulates the expression of alveolar macrophage macrophage colony-stimulating factor. The Journal of Immunology, 181, 235-242.

[16] Bonfield, T.L., Farver, C.F., Barna, B.P., Malur, A., Abraham, S., Raychaudhuri, B., Kavuru, M.S. and Thomassen, M.J. (2003) PPARg is deficient in alveolar macrophages from patients with alveolar proteinosis. American Journal of Respiratory and Critical Care Medicine, 29, 677-682. doi:10.1165/rcmb.2003-01480C

[17] Lennon, D.P. and Caplan, A.I. (2006) Isolation of human marrow-derived mesenchymal stem cells. Experimental Hematology, 34, 1604-1605. doi:10.1016/j.exphem.2006.07.014

[18] Dennis, J.E., Haynesworth, S.E., Young, R.G. and Caplan, A.I. (1992) Osteogenesis in marrow-derived mesenchymal cell porous ceramic composites transplanted subcutaneously: Effect of fibronectin and laminin on cell retention and rate of osteogenic expression. Cell Transplantation, 1, 23-32.

[19] Mori, S., Yoshikawa, N., Tokoro, T., Ikehara, S., Inoue, Y., Nishikawa, M. and Inada, M. (1996) Studies of retroorbital tissue xenografts from patients with Graves' ophthalmopathy in severe combined immunodeficient (SCID) mice: Detection of thyroid-stimulating antibody. Thyroid, 6, 275-281. doi:10.1089/thy.1996.6.275

[20] Abdallah, B.M. and Kassem, M. (2008) Human mesenchymal stem cells: From basic biology to clinical applications. Gene Therapy, 15, 109-116. doi:10.1038/sj.gt.3303067

[21] Bonfield, T.L., John, N., Barna, B.P., Kavuru, M.S., Thomassen, M.J. and Yen-Lieberman, B. (2005) Multiplexed particle-based anti-granulocyte macrophage colony stimulating factor (GM-CSF) assay: A pulmonary diagnostic test. Clinical and Diagnostic Laboratory Immunology, 12, 821-824

[22] Kube, D., Sontich, U., Fletcher, D. and Davis, P.B. (2001) Proinflammatory cytokine responses to $P$. aeruginosa infection in human airway epithelial cell lines. American Journal of Physiology-Lung Cellular and Molecular Physiology, 280, L493-L502.

[23] Zeitlin, P.L., Lu, L., Rhim, J., Cutting, G., Stetten, G., Kieffer, K.A., Craig, R. and Guggino, W.B. (1991) A cystic fibrosis bronchial epithelial cell line: Immortalization by adeno-12-SV40 infection. American Journal of Respiratory Cell and Molecular Biology, 4, 313-319. doi:10.1165/ajrcmb/4.4.313

[24] Bonfield, T.L., Hodges, C.A., Cotton, C.U. and Drumm, M.L. (2012) Absence of the cystic fibrosis transmembrane regulator $(C f t r)$ from myeloid-derived cells slows resolution of inflammation and infection. Journal of Leukocyte Biology, 92, 1111-1122.

[25] Bonfield, T.L., John, N., Malur, A., Barna, B.P., Culver, D.A., Kavuru, M.S. and Thomassen, M.J. (2005) Elevated monocyte chemotactic proteins 1,2 , and 3 in pulmonary alveolar proteinosis are associated with chemokine receptor suppression. Clinical Immunology, 114, 7985. doi:10.1016/j.clim.2004.09.004

[26] Hodges, C.A., Cotton, C.U., Palmert, M.R. and Drumm, M.L. (2008) Generation of a conditional null allele for Cftr in mice. Genesis, 46, 546-552. doi: $10.1002 /$ dvg. 20433

[27] Van Heeckeren, A.M. and Schluchter, M.D. (2002) Murine models of chronic Pseudomonas aeruginosa lung infection. Lab Animal, 36, 291-312. doi:10.1258/002367702320162405

[28] Bokarewa, M., Nagaev, I., Dahlberg, L., Smith, U. and Tarkowski, A. (2005) Resistin, an adipokine with potent proinflammatory properties. The Journal of Immunology, 174, 5789-5795.

[29] Stutz, A.M., Pickart, L.A., Trifilieff, A., Baumruker, T., Prieschl-Strassmayr, E. and Woisetschlager, M. (2003) The Th2 cell cytokines IL-4 and IL-13 regulate found in inflammatory zone $1 /$ resistin-like molecule a gene expression by a STAT6 and CCAAT/enhancer-binding protein-dependent mechanism. The Journal of Immunology, 170, 1789-1796.

[30] Capelli, A., Di Stefano, A., Lusuardi, M., Gnemmi, I. and Donner, C.F. (2002) Increased macrophage inflammatory protein-1a and macrophage inflammatory protein-1B levels in bronchoalveolar lavage fluid of patients affected by different stages of pulmonary sarcoidosis. American Journal of Respiratory and Critical Care Medicine, 165, 236-241. doi:10.1164/ajrccm.165.2.2106084

[31] Brown, K.L., Poon, G.F., Birkenhead, D., Pena, O.M., Falsafi, R., Dahlgren, C., Karlsson, A., Bylund, J., Hancock, R. E. and Johnson, P. (2011) Host defense peptide LL-37 selectively reduces proinflammatory macrophage responses. The Journal of Immunology, 186, 5497-5505. doi:10.4049/jimmunol.1002508

[32] Cott, A., Weldon, S., Buchanan, P.J., Schock, B., Ernst, R.K., McAuley, D.F., Tunney, M.M., Irwin, C.R., Elborn, J.S. and Taggart, C.C. (2011) Evaluation of the ability of 
LL-37 to neutralise LPS in vitro and ex vivo. PLoS One, 6 , e26525.

[33] Dennis, J.E. and Caplan, A.I. (1996) Differentiation potential of conditionally immortalized mesenchymal progenitor cells from adult marrow of a $\mathrm{H}-2 \mathrm{~Kb}$-tsA58 transgenic mouse. Journal of Cellular Physiology, 167, 523538. doi:10.1002/(SICI)1097-4652(199606)167:3<523::AID-J $\mathrm{CP} 16>3.0 . \mathrm{CO} ; 2-4$

[34] Hodges, C.A., Grady, B.R., Mishra, K., Cotton, C.U. and Drumm, M.L. (2011) Cystic Fibrosis growth retardation is not correlated with loss of Cftr in the intestinal epithelium. American Journal of Physiology-Gastrointestinal and Liver Physiology, 301, G528-G536. doi:10.1152/ajpgi.00052.2011

[35] Fang, X., Song, Y., Hirsch, J., Galietta, L.J., Pedemonte, N., Zemans, R.L., Dolganov, G., Verkman, A.S. and Matthay, M.A. (2006) Contribution of CFTR to apical-basolateral fluid transport in cultured human alveolar epithetlial type II cells. American Journal of Physiology-Lung Cellular and Molecular Physiology, 290, L242-L249. doi:10.1152/ajplung.00178.2005

[36] Nichols, D., Chmiel, J. and Berger, M. (2008) Chronic inflammation in the cystic fibrosis lung: Alterations in inter- and intracellular signaling. Clinical Reviews in Allergy \& Immunology, 34, 146-162. doi:10.1007/s12016-007-8039-9

[37] Witko-Sarsat, V., Sermet-Gaudelus, I., Lenoir, G. and Descamps-Latscha, B. (1999) Inflammation and CFTR: Might neutrophils be the key in cystic fibrosis? Mediators of Inflammation, 8, 7-11. doi:10.1080/09629359990658

[38] Sagel, S.D., Chmiel, J.F. and Konstan, M.W. (2007) Sputum biomarkers of inflammation in cystic fibrosis lung disease. Proceedings of the American Thoracic Society, $\mathbf{4}$, 406-417. doi:10.1513/pats.200703-044BR

[39] Chmiel, J.F., Berger, M. and Konstan, M.W. (2002) The role of inflammation in the pathophysiology of CF lung disease. Clinical Reviews in Allergy \& Immunology, 23, 5-27. doi:10.1385/CRIAI:23:1:005

[40] Konstan, M.W., VanDevanter, D.R., Rasouliyan, L., Pasta, D.J., Yegin, A., Morgan, W.J. and Wagener, J.S. (2010) Trends in the use of routine therapies in cystic fibrosis: 1995-2005. Pediatric Pulmonology, 45, 1167-1172. doi:10.1002/ppul.21315

[41] Meyerholz, D.K., Stoltz, D.A., Namati, E., Ramachandran, S., Pezzulo, A.A., Smith, A.R., Rector, M.V., Suter, M.J., Kao, S., McLennan, G., Tearney, G.J., Zabner, J., McCray Jr., P.B. and Welsh, M.J. (2010) Loss of cystic fibrosis transmembrane conductance regulator function produces abnormalities in tracheal development in neonatal pigs and young children. American Journal of Respiratory and Critical Care Medicine, 182, 1251-1261. doi:10.1164/rccm.201004-06430C

[42] Bruscia, E.M., Price, J.E., Cheng, E.C., Weiner, S., Caputo, C., Ferreira, E.C., Egan, M.E. and Krause, D.S. (2006) Assessment of cystic fibrosis transmembrane conductance regulator (CFTR) activity in CFTR-null mice after bone marrow transplantation. Proceedings of the National Academy of Sciences of the United States of
America, 103, 2965-2970. doi:10.1073/pnas.0510758103

[43] Bonfield, T.L., Koloze, M., Lennon, D.P., Zuchowski, B., Yang, S.E. and Caplan, A.I. (2010) Human mesenchymal stem cells suppress chronic airway inflammation in the murine ovalbumin asthma model. American Journal of Physiology: Lung Cellular and Molecular Physiology, 299, L760-L770. doi:10.1152/ajplung.00182.2009

[44] Bonfield, T.L., Nolan Koloze, M.T., Lennon, D.P. and Caplan, A.I. (2010) Defining human mesenchymal stem cell efficacy in vivo. Journal of Inflammation (London), 7, 51. doi:10.1186/1476-9255-7-51

[45] Matthay, M.A. (2010) Advances and challenges in translating stem cell therapies for clinical diseases. Translational Research, 156, 107-111. doi:10.1016/j.trsl.2010.07.007

[46] Matthay, M.A. (2009) Mesenchymally "stemming" angiogenesis. Blood, 113, 4131-4132. doi:10.1182/blood-2009-01-195396

[47] Matthay, M.A., Thompson, B.T., Read, E.J., McKenna Jr., D.H., Liu, K.D., Calfee, C.S. and Lee, J.W. (2010) Therapeutic potential of mesenchymal stem cells for severe acute lung injury. Chest, 138, 965-972. doi: $10.1378 /$ chest.10-0518

[48] Mei, S.H., Haitsma, J.J., Dos Santos, C.C., Deng, Y., Lai, P.F., Slutsky, A.S., Liles, W.C. and Stewart, D.J. (2010) Mesenchymal stem cells reduce inflammation while enhancing bacterial clearance and improving survival in sepsis. American Journal of Respiratory and Critical Care Medicine, 182, 1047-1057. doi:10.1164/rccm.201001-00100C

[49] Bonfield, T.L., Panuska, J.R., Hilliard, K.A., Hilliard, J.B., Ghnaim, H. and Berger, M. (1995) Inflammatory cytokines in cystic fibrosis lungs. American Journal of Respiratory and Critical Care Medicine, 152, 2111-2118. doi:10.1164/ajrccm.152.6.8520783

[50] Chmiel, J.F., Konstan, M.W., Knesebeck, J.E., Hilliard, J.B., Bonfield, T.L., Dawson, D.V. and Berger, M. (1999) IL-10 attenuates excessive inflammation in chronic pseudomonas infection in mice. American Journal of Respiratory and Critical Care Medicine, 160, 2040-2047. doi:10.1164/ajrccm.160.6.9901043

[51] Nemeth, K., Keane-Myers, A., Brown, J.M., Metcalfe, D.D., Gorham, J.D., Bundoc, V.G., Hodges, M.G., Jelinek, I., Madala, S., Karpati, S. and Mezey, E. (2010) Bone marrow stromal cells use TGF-beta to suppress allergic responses in a mouse model of ragweed-induced asthma. Proceedings of the National Academy of Sciences of the United States of America, 107, 5652-5657. doi:10.1073/pnas.0910720107

[52] Yagi, H., Soto-Gutierrez, A., Parekkadan, B., Kitagawa, Y., Tompkins, R.G., Kobayashi, N. and Yarmush, M.L. (2010) Mesenchymal stem cells: Mechanisms of immunomodulation and homing. Cell Transplantation, 19, $667-$ 679. doi:10.3727/096368910X508762

[53] Matthay, M.A., Goolaerts, A., Howard, J.P. and Lee, J.W. (2010) Mesenchymal stem cells for acute lung injury: Preclinical evidence. Critical Care Medicine, 38, S569S573. doi:10.1097/CCM.0b013e3181f1ff1d

[54] Chen, C.I., Schaller-Bals, S., Paul, K.P., Wahn, U. and 
Bals, R. (2004) Beta-defensins and LL-37 in bronchialveolar lavage fluid of patients with cystic fibrosis. Journal of Cystic Fibrosis, 3, 45-50. doi:10.1016/i.jcf.2003.12.008

[55] Rigo, I., McMahon, L., Dhawan, P., Christakos, S., Yim, S., Ryan, L.K. and Diamond, G. (2012) Induction of triggering receptor expressed on myeloid cells (TREM-1) in airway epithelial cells by $1,25(\mathrm{OH})(2)$ vitamin $\mathrm{D}(3)$. Innate Immunity, 18, 250-257.

[56] Golec, M. (2007) Cathelicidin LL-37: LPS-neutralizing, pleiotropic peptide. Annals of Agricultural and Environmental Medicine, 14, 1-4.

[57] Desgranges, S., Le, P.F., Daly, A., Lydon, J., Brennan, M., Rai, D.K., Subasinghage, A.P., Hewage, C.M., Cryan, S.A., Greene, C., McElvaney, N.G., Smyth, T.P., Fitzgerald-Hughes, D., Humphreys, H. and Devocelle, M. (2011) In vitro activities of synthetic host defense propeptides processed by neutrophil elastase against cystic fibrosis pathogens. Antimicrobial Agents and Chemotherapy, 55, 2487-2489. doi:10.1128/AAC.01384-10

[58] Bergsson, G., Reeves, E.P., McNally, P., Chotirmall, S.H.,
Greene, C.M., Greally, P., Murphy, P., O’Neill, S.J. and McElvaney, N.G. (2009) LL-37 complexation with glycosaminoglycans in cystic fibrosis lungs inhibits antimicrobial activity, which can be restored by hypertonic saline. The Journal of Immunology, 183, 543-551. doi:10.4049/jimmunol.0803959

[59] Bucki, R., Byfield, F.J. and Janmey, P.A. (2007) Release of the antimicrobial peptide LL-37 from DNA/F-actin bundles in cystic fibrosis sputum. European Respiratory Journal, 29, 624-632. doi:10.1183/09031936.00080806

[60] Bruscia, E.M., Zhang, P.X., Ferreira, E., Caputo, C., Emerson, J.W., Tuck, D., Krause, D.S. and Egan, M.E. (2009) Macrophages directly contribute to the exaggerated inflammatory response in cystic fibrosis transmembrane conductance regulator ${ }^{-/}$mice. American Journal of Respiratory Cell and Molecular Biology, 40, 295-304. doi:10.1165/rcmb.2008-0170OC

[61] Matthay, M.A. (2008) Treatment of acute lung injury: Clinical and experimental studies. Proceedings of the American Thoracic Society, 5, 297-299. doi:10.1513/pats.200708-141DR 